18 Billings JJ. Natural family planning. Lancet 1976;ii:579.

19 Marshall J. Natural family planning. Lancet 1976;ii:685.

20 Billings J. Natural family planning. Lancet 1976;ii:969.

21 Marshall J. Natural family planning. Lancet 1976;ii: 1085

22 Reid KM. Choice of method. In: Loudon N, ed. Handbook of family planning. Edinburgh: Churchill Livingstone, 1985:25-39.

23 World Health Organisation. A prospective multicentre trial of the ovulation method of natural family planning. I. The teaching phase. Fertil Steril 1981;36:152-8.

24 World Health Organisation. A prospective multicentre trial of the ovulation method of natural family planning. II. The effectiveness phase. Fertil Steril 1981;36:591-8.

25 World Health Organisation. A prospective multicentre trial of the ovulation method of natural family planning. III. Characteristics of the menstrual cycle and of the fertile phase. Fertil Steri 1983;40:773-8.

26 World Health Organisation. A prospective multicentre trial of the ovulation method of natural family planning. IV. The outcome of pregnancy. Fertil Steril 1984;41:593-8.

27 World Health Organisation. A prospective multicentre trial of the ovulation method of natural family planning. V. Psychosexual aspects. Fertil Steril 1987;47:765-72.

28 Perez A, Zabala A, Larrain A, Widmer S, Nunez M, Baranda B, et al. The clinical efficiency of the ovulation method (Billings). Rev Chil Obstet Ginecol 1983;48:97-102

29 Rice RJ, Lanctot CA, Garcia-Devesa C. Effectiveness of the symptothermal method of natural family planning: an international study. Int $f$ Fertil 1981;26:222-30.

30 Barbato M, Bertolotti G. Natural methods for fertility control: a prospective study. Int f Fertil 1988;33(suppl):48-51.
31 Frank-Hermann $P$, Bremme $M$, Rosmus $t$, Kunkel W. Use-effectiveness of a symptothermal method in Germany. In: Schaitouits H, ed. Proceedings of 4th European congress IFFLP/FIDAF Vienna, Austria. Vienna: Institut für 4th European congress IFFLP/FIL

32 Bonnar J. Natural family planning including breast feeding. In: Mishell DR, ed. Advances in fertility research. New York: Raven Press, 1982:1-18.

33 Ghosh AK, Saha S, Chattergee G. Symptothermia vis a vis fertility control. foumal of Obstetrics and Gynaecology of India 1982;32:443-7.

34 Roetzer J. Symptothermal methods of natural family planning. International Review of Natural Family Planning 1981;5:200-2.

35 Kambic RT, Gray RH, Lanctot CA, Martin MC, Wesley R, Cremins R. Evaluation of natural family planning programs in Liberia and Zambia. Am $\mathcal{F}$ Obstet Gynecol 1991;165:2078.

36 Frank-Herrmann P, Freundl G, Burr S, Bremme M, Doring GK, Godehardt EAJ, et al. Effectiveness and acceptability of the symptothermal method of natural family planning in Germany. Am f Obstet Gymecol 1991;165:2052-4.

37 Dorairai K. The modified mucus method in India. Am 7 Obstet Gynecol 1991;165:2066-7.

38 Kelly J. Audit of health services in Gurage. F Trop Pediatr 1992:38:206-7.

39 Clubb EM, Pyper CM, Knight J. A pilot study on teaching natural family planning in general practice. In: Natural family planning: current knowledge and new strategies for the 1990s. Washington, DC: Georgetown University, 1990:130-2.

40 Ryder REJ, Depares J, Norman C, Walker S, Scanlon MF. Ovarian ultrasonography and the precision of the symptoms of ovulation. Clin Sci 1985;69(suppl 12):17P.

(Accepted 28 fuly 1993)

\title{
Economic Evaluation and Health Care
}

\section{Costs and cost-minimisation analysis}

\section{Ray Robinson}

This is the second in a series of articles that describe the ways in which methods of economic evaluation may be used to assess the economic costs and consequences associated with different forms of health care intervention.
Institute for Health Policy

Studies, University of

Southampton,

Southampton SO9 5NH

Ray Robinson, professor of

health policy

$B M \mathcal{F} 1993 ; 307: 726-8$
Whatever kind of economic evaluation you plan to undertake, the costs must be assessed. In health care these are first of all divided into costs borne by the NHS (like drugs), by patients and their families (like travel), and by the rest of society (like health education). Next the costs have to be valued in monetary terms; direct costs, like wages, pose little problem, but indirect costs (like time spent in hospital) have to have values imputed to them. And that is not all: costs must be further subdivided into average, marginal, and joint costs, which help decisions on how much of a service should be provided. Capital costs (investments in plant, buildings, and machinery) are also important, as are discounting and inflation. In this second article in the series Ray Robinson defines the types of costs, their measurement, and how they should be valued in monetary terms.

Cost-minimisation analysis is an appropriate evaluation method to use when the case for an intervention has been established and the programmes or procedures under consideration are expected to have the same, or similar, outcomes. In these circumstances, attention may focus on the cost side of the equation to identify the least costly option.

The analysis of costs that forms the basis of costminimisation analysis is common to all forms of economic evaluation, and so the following discussion will apply also to applications of cost-effectiveness, cost-utility, and cost-benefit analysis.

\section{Which costs should be included?}

If the evaluation is being made from the widest perspective-namely, the viewpoint of society as a whole-then three main categories of costs must be considered:

- Health service costs

- Costs borne by patients and their families

- External costs borne by the rest of society.

\begin{tabular}{l} 
Summary \\
\hline - Cost-minimisation analysis should be used when \\
the outcomes of alternative programmes are the same \\
or similar \\
- From a societal perspective, costs include: health \\
service costs, costs borne by patients and their families \\
and external costs borne by the rest of society \\
- Costs should reflect opportunity costs and may be \\
valued in terms of market prices or shadow prices \\
- Marginal costs are often lower than average costs \\
- Discounting is necessary to express costs on a \\
common basis (present values) when they are incurred \\
at different points in time \\
- Methods for taking account of inflation need to \\
distinguish between changes in the general price level \\
and changes in relative prices
\end{tabular}

\section{HEALTH SERVICE COSTS}

These will include staff time, medical supplies (including drugs), hotel services, use of capital equipment, and overheads such as heating and lighting. These items may be divided into variable costs which vary according to the level of activity (for example, staff time) and fixed costs which are incurred whatever the level of activity (for example, heating and lighting) In the long run, practically all costs become variable because those that are fixed in the short run may be varied-for example, by opening and closing wards, and by building new hospitals. In economic evaluation all health service costs-both fixed and variable-are referred to as direct costs.

\section{COSTS BORNE BY PATIENTS AND THEIR FAMIIIES}

These will include out of pocket expenses such as travel, and any costs resulting from caring activities undertaken by the family. These are both direct cost items. In addition, there may also be indirect costs such as income lost because of absence from work 


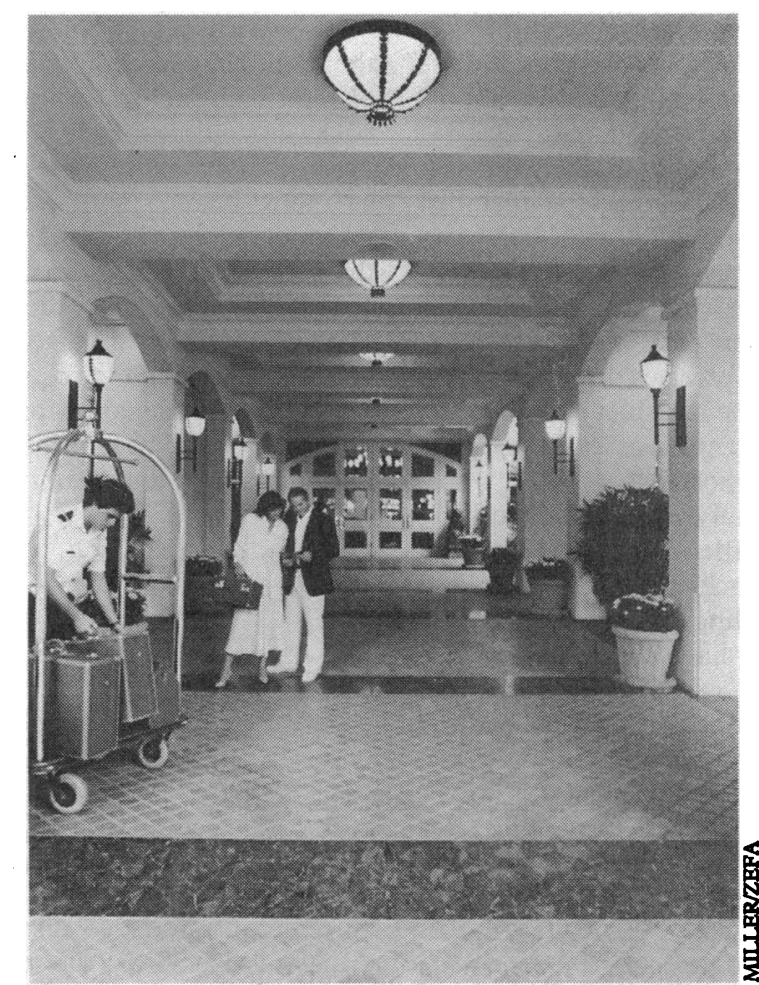

What exactly are "hotel costs?"

(which is a production loss to society) and any psychological stress experienced by patients, or their families, or both.

\section{EXTERNAL COSTS}

These occur when people not directly involved in a programme experience increased costs because of it. In most cases these effects are too small and diffuse to merit inclusion in the analysis, but there may be some occasions when they are large enough to require attention. For example, public health legislation enforcing antipollution standards or specifying water purification levels may lead to increases in manufacturing costs and consumer prices (as well as providing health benefits).

\section{How should costs be valued?}

I have dealt with the identification of costs and their measurement in physical units (hours of staff time, hours of operating theatre use, quantities of drugs, and so on). The next stage of the analysis requires that they should be valued in monetary terms.

For most direct cost items market prices will be available. Nursing time can therefore be valued at the appropriate hourly rate; medical and surgical supplies can be valued at the prices charged by suppliers; heating and lighting can be valued at the appropriate tariffs; and so on.

Strictly speaking, economic evaluation should seek to value all inputs in terms of their opportunity coststhat is, their value in their next best use. This measures what is being given up to use resources in health care. Sometimes opportunity costs will diverge from market prices. If, for example, a nurse would otherwise be unemployed, then his or her opportunity cost would be zero and not the hourly wage. For most practical purposes, however, it is usual to use market prices unless there is strong evidence to suggest that they diverge appreciably from opportunity costs.

Indirect costs, for which there are no market prices, pose a more difficult problem of valuation. Some method has to be used to impute values to them. This is known as "shadow pricing," and time costs provide a good example. When time is spent in hospital by a patient, or on caring at home by a relative, and this displaces work time, it is usual practice to use the relevant wage to value the lost time. If it is not work time that is displaced, however, other measures must be used. The Department of Transport has carried out extensive research in the area of time valuation and its work can be drawn upon to value health time costs. The latest departmental estimates issued in 1989 (at 1988 average prices) place an average value on work time (including overheads such as national insurance and pension payments) of $£ 8.42 /$ hour and of $£ 2.08 /$ hour on non-working time.'

\section{Average, marginal, and joint costs}

Most decisions in health care are not concerned with whether or not a service should be provided, or whether or not a particular procedure should be undertaken, but with how much of the service should be provided. That is, should existing levels of provision by expanded or contracted? For example, should the existing provision of day care for people with mental illness be expanded and, if so, by how much? What family planning services should be made available? How many patients presenting with head injuries should have computed tomograms? All these decisions require that attention should be focused on marginal costs-that is, the change in total costs resulting from a marginal change in activity.

In the short run there is often an important difference between the marginal costs of an activity and its average cost, where the average cost is defined as the total costs divided by the total number of units of output (table I). An example is provided by a study of the cost effectiveness of antihyperlipaemic treatment in the prevention of coronary heart disease. ${ }^{2}$ In this study the marginal cost was calculated per life year saved of continuing drug treatment for successive periods of five additional years for patients between 35 and 70 years of age. These indicated large differences between average and marginal cost effectiveness, as marginal costs increased quite steeply after 55 years of age.

Another context in which the distinction between average and marginal costs is important is in relation to duration of hospital stay of inpatients. Many new procedures have reduced the amount of time necessary for a patient to remain in hospital and thereby yield cost savings. When valuing these savings, however, it is important to bear in mind that using average costs/ day will generally overstate the savings as the later days of a stay usually cost less than the earlier ones. It is the marginal costs/day that is the relevant measure.

Yet another problem of cost measurement arises in connection with joint costs. Often a single production process can result in multiple outputs. For example, a single chemical analysis of a blood sample can diagnose the presence of many diseases. How should the cost be allocated to each diagnosis? Similarly, within a hospital setting, there are many common services (like medical records, radiology, operating theatres, laundry, catering, and cleaning) that contribute to a number of specialties. Economic evaluation requires some method for allocating the joint costs of these services to individual programmes or procedures. There are several methods which may be used to do this. Most of them use some physical unit of utilisation, such as the number of laboratory tests, hours of operating theatre use, or square metres of ward space, to apportion total laboratory, operating theatre, and ward cleaning costs. ${ }^{3}$

\section{Capital costs}

Investments in buildings, plant, and equipment that yield a flow of services over a number of years give rise 
to capital costs. Generally, investment expenditure will be undertaken at the beginning of a project but the use of items of capital equipment will generate annual capital costs over the lifetime of the asset.

These costs have two components-namely, interest and depreciation. Interest costs should be included even if the asset was not acquired with borrowed money because tying up money in an item of capital equipment involves an opportunity cost-that is, interest foregone. Depreciation costs arise because of the wear and tear that an asset receives through use and the consequent reduction in the length of its useful life. (Note, however, that land is a capital asset which is not assumed to incur depreciation costs.)

Sometimes an item of capital expenditure is unique to a particular use and has little or no alternative use value (opportunity cost). In such cases, it is referred to as a sunk cost. A hospital building or an item of medical equipment may, for example, have considerable value in its existing use but little resale value. This can provide a powerful case for continuing to use existing assets instead of undertaking new investments because, in an economic evaluation, sunk costs should not be included among annual capital costs. In practice, this consideration is likely to be more important in the case of major capital developments than of individual procedures.

The NHS and Community Care Act introduced a system of capital charges into the NHS. From April 1991, all providers have been required to keep registers of assets valued in excess of $£ 1000$ and to calculate interest and depreciation charges on them. These accounts should provide useful information for the calculation of capital costs in future economic evaluations.

\section{Discounting}

The current (operating) costs associated with most projects can be expected to extend over a number of years into the future, but their time profiles may differ. In the case of many preventive procedures, such as treatment for hypertension, costs will be incurred regularly over a number of years. The alternative of no preventive treatment may well incur zero expenditure in the early years but incur the costs of surgery earlier than would otherwise have been the case. Discounting offers a means of standardising different cost time profiles so that total costs can be compared.

Discounting is based on the assumption that costs incurred in the immediate future are of greater importance than costs incurred in the distant future. This is because earlier access to finance would permit investment at a positive rate of interest, thereby yielding a larger sum in the future (there is an opportunity cost) or because people and society attach more importance to current opportunities than to future ones (known as "positive time preference").

For these reasons, economic evaluation "weights" costs by a discount rate, according to the year in which they accrue, before adding them up and expressing total costs in present value terms (values in the current year).

\begin{tabular}{|c|c|c|c|c|c|c|c|}
\hline \multicolumn{8}{|c|}{ Discounting formula } \\
\hline Total cost $=$ & $\begin{array}{c}\text { Year } 0 \\
\mathrm{C}_{0}\end{array}$ & + & $\begin{array}{c}\text { Year } 1 \\
\mathrm{C}_{1}\end{array}$ & $\begin{array}{c}\text { Year } 2 \\
\mathrm{C}_{2}\end{array}$ & $\begin{array}{c}\text { Year } 3 \\
\mathrm{C}_{3}\end{array}$ & $\ldots$ & $\begin{array}{c}\text { Year n } \\
\mathrm{C}_{\mathrm{n}}\end{array}$ \\
\hline & & & $1+r$ & $(1+r)^{2}$ & $(1+r)^{3}$ & & $(1+r)^{n}$ \\
\hline
\end{tabular}

Where $C=$ annual cost, $n=$ discount rate and years, $j=0 \ldots n$
In essence, discounting is the reverse application of the more familiar compound interest formula-instead of sums being calculated forwards, they are discounted backwards. Fortunately, the application of discounting does not require close familiarity with the formula as many finance and accounting textbooks include discount tables. These indicate the present values of the pound at different discount rates.

Table II shows how present discounted values will vary for selected combinations of the discount rate and the years in which the costs accrue. Looking across the second row of the table, for example, shows that in the fifth year $£ 1$ will be worth $86 \mathrm{p}$ at a discount rate of $3 \%$, but only $68 \mathrm{p}$ at a discount rate of $8 \%$. The Treasury's

TABLE II-Present value of $£ 1$

\begin{tabular}{lcccccc}
\hline & \multicolumn{6}{c}{ Discount rate } \\
\cline { 2 - 7 } Year & $3 \%$ & $4 \%$ & $5 \%$ & $6 \%$ & $7 \%$ & $8 \%$ \\
\hline 1 & 0.9709 & 0.9615 & 0.9524 & 0.9434 & 0.9346 & 0.9259 \\
5 & 0.8626 & 0.8219 & 0.7835 & 0.7473 & 0.7130 & 0.6806 \\
10 & 0.7441 & 0.6756 & 0.6139 & 0.5584 & 0.5083 & 0.4632 \\
15 & 0.6419 & 0.5553 & 0.4810 & 0.4173 & 0.3624 & 0.3152 \\
20 & 0.5537 & 0.4564 & 0.3769 & 0.3118 & 0.2584 & 0.2145 \\
25 & 0.4776 & 0.3751 & 0.2953 & 0.2330 & 0.1842 & 0.1460 \\
\hline
\end{tabular}

current recommended discount rate for public sector projects is $6 \%$. Given the sensitivity of valuations to the choice of discount rate, however, and the fact that the ranking of different projects with different time profiles could depend on the rate chosen, it is good practice to compute costs in terms of a range of discount rates.

\section{Inflation}

Most programmes that extend over several years will be affected by inflation. It is important, however, to distinguish between changes in the general price level and changes in relative prices. In the case of general inflation there will be no change in the relative cost of inputs (their opportunity costs remain constant). As such, all future inputs can be valued at current prices and discounted by a real (excluding inflationary effect) rate of interest.

If, however, some input prices are expected to increase more than others there will be relative changes in their opportunity costs and these need to be taken into account. One way of doing this is to use the general rate of inflation as a benchmark and to adjust the future prices of individual inputs - upwards or downwardsby an amount that reflects the difference between their rate of inflation and the general rate. Thereafter, all costs should once again be discounted by the same real rate of interest.

1 Department of Transport. Values of time and vehicle operation costs for 1989. Highways Economics Note No 2; Annex 2, 1989.

2 Oster G, Epstein AM. Cost-effectiveness of antihyperlipemic therapy in the prevention of coronary heart disease. FAMA 1987;258:2381-7.

3 Drummond MF, Stoddart GL, Torrance GW. Methods for the economic evaluation of health care programmes. Oxford: Oxford University Press, 1987.

\section{Correction}

Rationing in action. Priority setting in the NHS: reports from six districts

Due to an author's error, the table in this article by Chris Ham (14 August, pp 435-8) was not properly attributed to the researchers whose data are presented there. The table and the full study have now been published: Bowling A, Jacobson B, Southgate L. Health service priorities: explorations in consultation of the public and health professionals on priority setting in an inner London health district. Soc Sci Med 1993;37:851-7. This describes in full the methodology used in the study, which was a completely independent exercise funded by the King's Fund and was independent of the health authority. 